\title{
АКТУАЛЬНЫЕ ВОПРОСЫ ОРГАНИЗАЦИИ ВЗАИМОДЕЙСТВИЯ И КООРДИНАЦИИ ДЕЙСТВИЙ СУБЪЕКТОВ ПРИ ОБЕСПЕЧЕНИИ ЭКОНОМИЧЕСКОЙ БЕЗОПАСНОСТИ КОМПАНИИ (ФИРМЫ)
}

\author{
(c) 2021 Малышев Сергей Яковлевич \\ доцент, кандидат юридических наук, доцент кафедры финансов, \\ денежного обращения и экономической безопасности \\ Уфимский государственный авиационный технический университет, Россия, Уфа \\ Email:malyss5@yandex.ru
}

В статье исследуются вопросы организации содействия, сотрудничества и взаимодействия заинтересованных субъектов при обеспечении экономической безопасности компании (фирмы). Рассмотрено соотношение между собой содержания понятий «содействие», «сотрудничество» и «взаимодействие» субъектов, определены структурные элементы организационных систем, выявлен закономерный характер системной связи.

Ключевые слова: содействие, сотрудничество, взаимодействие, координация действий, субъекты, предмет взаимодействия, организационная система, системные связи.

Актуальность вопросов организации взаимодействия и координации действий определяется реалиями сегодняшнего дня, когда на совещаниях, конференциях и коллегиях различного уровня руководители компаний (фирм), правоохранительных органов и министерств говорят о существующем системном сбое в организации взаимодействия между отдельными ведомствами, подразделениями и службами компании. Главная, на наш взгляд, проблема в вопросе организации взаимодействия, не смотря на имеющийся в настоящее время обширный научный материал по данной теме - это отсутствие системного подхода в изучении этого социального явления совместной деятельности субъектов при решении конкретных задач. Для системного подхода в изучении проблем организации взаимодействия важно определить основные структурные элементы в системе ее организации и тщательно исследовать существующие между ними системные связи, в том числе и правоотношения, возникающие между этими элементами в процессе взаимодействия. В начале нашего исследования указанной проблемы важно уточнить содержание понятия «взаимодействие». В соответствии со словарем русского языка С.И.Ожегова под взаимодействием понимается взаимная связь двух явлений [1]. В связи с этим, необходимо исследовать содержательную сторону рассматриваемых явлений, т.е. в чем обнаруживается сущность взаимодействия. Следует отметить, что взаимодействие, как взаимная связь двух явление, прежде всего, характеризуется согласованностью действий заинтересованных субъектов, т.е. действий, в котором «достигнуто единство, согласие» [2]. Однако, согласованность действий субъектов может достигаться не только при их взаимодействии, но также при осуществлении между ними содействия и сотрудничества. В настоящее время существует ошибочное мнение в том, что любая согласованность действий субъектов достигается только лишь содействием, сотрудничеством и взаимодействием между ними. Для того, чтобы разобраться в исследуемой связи явлений, важно выяснить структуру построения системы организации взаимодействия, содействия и сотрудничества, т.е. установить из каких основных элементов состоят данные организационные системы и какова закономерность системной связи между ее структурными элементами.

Очевидным является тот факт, что взаимодействие, содействие и сотрудничество всегда происходит между заинтересованными в этом субъектами. Следовательно, субъекты являются основными элементами рассматриваемых явлений, без которых не мыслимо существование последних. Важная правовая характеристика указанных субъектов состоит в том, что эти субъекты в правовом отношении друг к другу являются относительно самостоятельными, т.е. между ними не должны существовать властно-управленческие отношения. Властно-управленческие отношения предпо- 
лагают наличие вопросов власти и подчинения между субъектами, т.е. между руководителем (начальником) и подчиненным (работником), согласованность действий которых решается директивным способом в приказном порядке со стороны руководителя (начальника). Можно ли в данном случае говорить о содействии, сотрудничестве или взаимодействии между начальником и подчиненным? Если на этот вопрос ответить утвердительно, то в дальнейшем наши попытки объективно исследовать содержание содействия, сотрудничества, взаимодействия и разграничить эти понятия между собой не будут иметь успеха, так как организационная связка «начальник - подчиненный» характеризуется своим единством. Данное единство между руководителем и подчиненным (работником) исходит и основывается на их возможностях в решении общей для них задачи, достижении единой цели. Возможности руководителя (начальника) и возможности подчиненного (работника) - это две составные части одной целой организационной системы «начальник - подчиненный» и руководителям этого не следует забывать. Так, единство указанной организационной системы проявляется в том, что имеющиеся возможности подчиненного (работника) в решении конкретной задачи, в конечном итоге, определяют возможности и самого руководителя (начальника) в решении этой задачи, а возможности руководителя (начальника) качественно дополняют возможности его подчиненного (работника). В рассматриваемой организационной системе «начальник - подчиненный» отсутствует относительная правовая самостоятельность между этими субъектами, здесь в основе этих правоотношений лежат властно-управленческие отношения, которые сами по себе по своей природе не могут непосредственно создать отношений содействия, сотрудничества и взаимодействия, они (властно-управленческие отношения) являются как бы правовым фоном для существования отношений взаимодействия. Ниже мы рассмотрим почему.

Потенциальные оппоненты могут нам возразить, почему руководитель (начальник) не может содействовать, сотрудничать и взаимодействовать с подчиненным (работником), ведь они действуют согласованно в решении общей для них задачи? Прежде чем ответить на этот вопрос, рассмотрим, ради чего организуется содействие, сотрудничество и взаимодействие между субъ- ектами?

Ответ на этот вопрос так или иначе мы раскрыли ранее - содействие, сотрудничество и взаимодействие организуется ради использования в решении конкретной задачи (достижении цели) возможностей содействующих, сотрудничающих и взаимодействующих субъектов. Еще раз подчеркнем, что властноуправленческие отношения в организационной системе «начальник - подчиненный» не разъединяют возможности данных субъектов, а наоборот объединяют их в одно единое целое. Иначе говоря, возможности подчиненного (работника) - есть возможности руководителя (начальника) и, наоборот, возможности руководителя (начальника) - есть возможности подчиненного (работника) в решении общей для них задачи, достижении единой цели.

Таким образом, не с каждым субъектом может организовываться содействие, сотрудничество и взаимодействие в решении конкретной задачи, а только с тем субъектом, который обладает необходимыми возможностями для решения этой задачи. Следовательно, для организации содействия, сотрудничества и взаимодействия между субъектами необходимо знать их возможности. Только зная возможности содействующего, сотрудничающего и взаимодействующего субъекта можно четко, конкретно и ясно определить предмет содействия, сотрудничества и взаимодействия.

Следует отметить, что согласованность действий субъектов при содействии, сотрудничестве и взаимодействии не может осуществляться «на пустом месте», для их осуществления необходимо наличие основания (базиса) для организации содействия, сотрудничества, взаимодействия. В качестве основания (базиса) организации содействия, сотрудничества, взаимодействия могут выступать различные формы договоров (устный, письменный), нормативные правовые акты, в том числе на законодательном уровне, властные органы, руководители (начальники), имеющие властно-управленческие функции. Рассматриваемое основание (базис) является одним из элементов системы организации содействия, сотрудничества и взаимодействия.

Далее назрела необходимость рассмотрения вопроса о соотношении между собой систем организаций содействия, сотрудничества и взаимодействия. Важно отметить, что для всех 
указанных выше систем организаций общими являются составляющие их структурные элементы:

- субъекты;

- предмет содействия, сотрудничества, взаимодействия;

- основание (базис);

- конкретная решаемая задача (цель).

Кроме того, рассматриваемые организационные системы включают следующий общий для них существенный признак - все они направлены для определения и осуществления согласованности действий между заинтересованными субъектами в решении конкретной задачи. Исходя из сказанного, можно изначально предположить, что различия указанных организационных систем кроятся не в их структурном построении, а в содержательной стороне данных явлений, которая в свою очередь должна определять степень (уровень) связанности, тесноты, согласованности и единства действий субъектов содействия, сотрудничества и взаимодействия, $а$ также оперативности и своевременности решения вопроса о ликвидации негативных условий для таких действий субъектов. В связи с этим, справедливо возникает вопрос, каким образом достигаются такие качественные характеристики организационных систем содействия, сотрудничества и взаимодействия?

Ответ на поставленный вопрос требует детального исследования содержательной стороны существующих системных связей между структурными элементами рассматриваемых организационных систем, которые на представленной схеме обозначены в виде стрелок (см. схему № 1 ).

В начале рассмотрим системную связь, существующую между основанием (базисом) и субъектами указанной системы организации, на основе которой определяются полномочия последних на организацию содействия, сотрудничества и взаимодействия.

Если субъекты содействия, сотрудничества и взаимодействия серьезно, добросовестно и со всей ответственностью готовы решать стоящие перед ними задачи и совместно достигать поставленные цели, то форма основания (базиса) указанных организационных систем не важна, так как задача будет решена, а цель достигнута. Другое дело, если происходит сбой системы организации содействия, сотрудничества, взаимодействия, то субъекты непосредственно должны обратиться к основанию (базису) для решения вопроса о восстановлении нарушенного положения о согласованности действий между ними. Именно в этой ситуации решается вопрос об оперативности восстановления положения согласованности действий между субъектами содействия, сотрудничества и взаимодействия в решении конкретной задачи, достижении определенной цели.

В связи с этим, справедливо возникает вопрос, каким образом следует организовать содействие, сотрудничество, взаимодействие

\section{Схема № 1}

\section{система организации содействия, сотрудничества и взаимодействия}

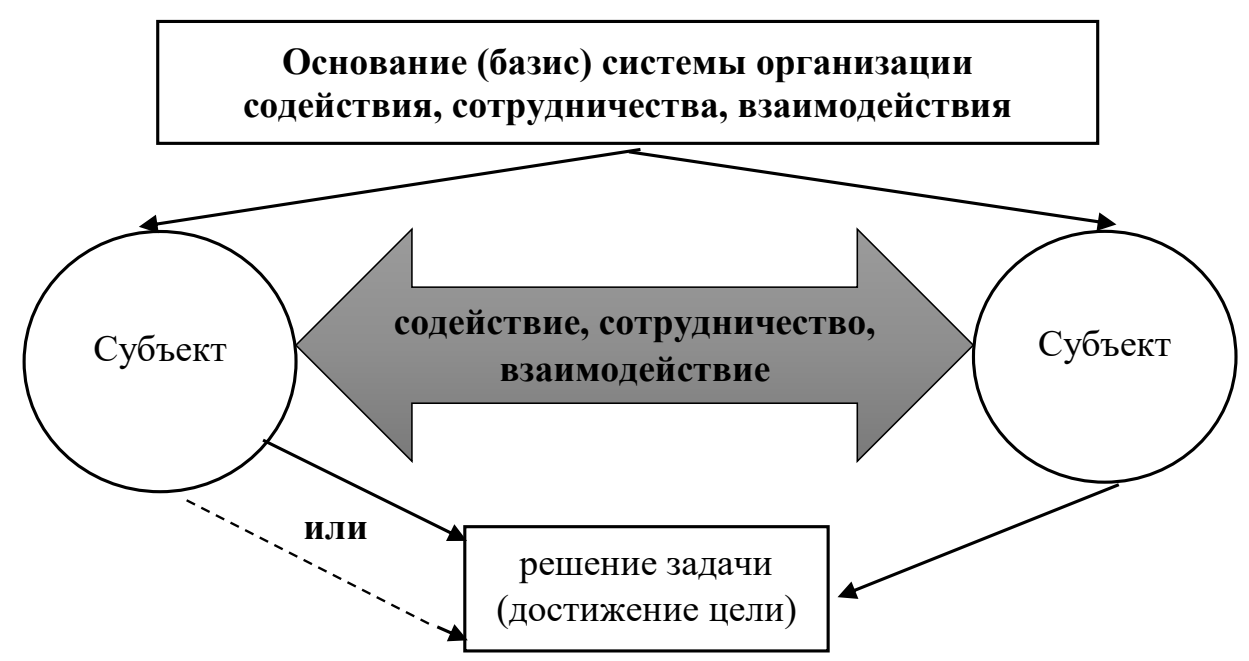


между заинтересованными субъектами, чтобы избежать сбоя в их согласованности действий? А если этот сбой произошел, то как в максимально короткие сроки его своевременно и оперативно ликвидировать? Ответы на данные вопросы очень актуальны для решения оперативно-тактических задач оперативными подразделениями правоохранительных органов и специальных служб, когда цена такого сбоя очень велика и может стоить жизни людей.

Для того, чтобы рассматриваемая система организации характеризовалась высокой степенью (уровнем) связанности, тесноты, согласованности и единством действий субъектов содействия, сотрудничества и взаимодействия, а также оперативностью и своевременностью решения вопроса о недопущения и ликвидации негативных условий, которые способствуют возникновению сбоя в согласованности действий заинтересованных субъектов, указанная организационная система должна соответствовать следующим существенным признакам ее характеризующим:

- субъекты должны быть действительно заинтересованы в решении конкретной задачи (достижении поставленной цели), которые для них являются общими и едиными;

- в обязательном порядке полномочия субъектов на организацию согласованности действий между ними определяются авторитетным властным органом или должностным лицом, наделенным властно-управленческими функциями (руководители, начальники различного уровня);

- основание (базис) системы организации в лице авторитетного органа или должностного лица при необходимости, в случае возникно- вения сбоя в согласованности действий между субъектами, в состоянии осуществить координацию действий между последними.

Координация действий - это властноуправленческие правоотношения, возникающие между руководителем (начальником) и подчиненными (работниками) в осуществлении последними согласованности действий в решении конкретной задачи, достижении единой цели. Таким образом, согласованность действий между субъектами в решении конкретной задачи, может достигаться двумя следующими путями:

- создания системы организации содействия, сотрудничества и взаимодействия;

- осуществление со стороны авторитетного властного органа или должностного лица (руководителя, начальника) координации действий между субъектами без создания системы организации содействия, сотрудничества и взаимодействия между ними.

Важно отметить, что система организации содействия, сотрудничества и взаимодействия не исключает из своего содержания вопросов организации координации действий со стороны руководителя (начальника). Они должны гармонично дополнять друг друга.

Из вышесказанного можно сделать вывод, что система организации содействия, сотрудничества и взаимодействия - это явления одного порядка, которые отличаются друг от друга лишь степенью (уровнем) связанности, тесноты, согласованности и единства действий субъектов содействия, сотрудничества и взаимодействия, а также оперативности и своевременности решения вопроса о ликвидации негативных условий для таких действий субъектов, в том числе и их координации.

\section{Библиографический список}

1. С. И. Ожегов. Словарь русского языка - М.: Государственное издательство иностранных и национальных словарей, 1960. С. 74.

2. С. И. Ожегов. Указ. работа. С. 732.

3. Федеральный закон от 29 июля 2004 г. № 98-ФЗ «О коммерческой тайне» // Собрание законодательства РФ. 2004. № 32. Ст. 3283. 